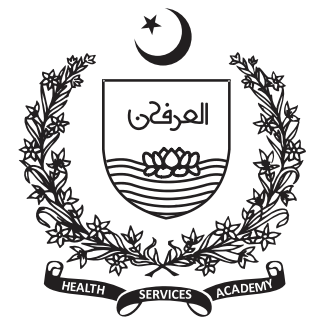

13rd Year MBBS student, Fazaia Medical College, Air University, Islamabad

24th Year MBBS student, Fazaia Medical College, Air University, Islamabad

${ }^{3}$ Associate Professor, Community Medicine, Fazaia Medical College, Air University, Islamabad.

${ }^{4}$ Associate Professor of Medicine, Islamic International Medical College, Riphah International University

Corresponding Author: Dr. Arshia Bilal drarshiabilal@yahoo.com

\section{Compliance and Etiquettes of Using Face Masks in Public during COVID-19 Pandemic: A Community-Based Survey from Islamabad, Pakistan}

Mishaal Fazal ${ }^{1}$, Talha Khawar ${ }^{1}$, Zawar Raza², Laiba Maryam², Arshia Bilal ${ }^{3}$ Shamaila Burney ${ }^{4}$

\section{Abstract}

Background: To determine the frequency of general public compliant to face mask and also to evaluate knowledge and practice of using face mask in accordance with World Health Organization (WHO) and National Institute of Health $(\mathrm{NIH})$ guidelines in our community.

Methods: A cross-sectional descriptive design was adopted. A sample of 190 people was recruited from public areas in Islamabad during the COVID-19 pandemic. The study was conducted over a period of two months between November and December 2020. Knowledge and etiquettes of face mask use were evaluated with the help of a selfdeveloped questionnaire based on WHO and NIH guidelines. Statistical tests were applied to understand the association of knowledge with etiquettes and also to see the effects of demographic variables on them.

Results: This study revealed that one fourth of the sample population was not wearing face masks in public. More than half were not concerned about COVID-19 pandemic and only one third knew about the national policy related to face mask usage. Only one-tenth of the population wore the correct type of mask recommended for general public use (cloth mask). The participant's performance in the etiquette aspect of using face mask was also poor.

Conclusion: The general public is unaware of Pakistan's national policy on face masks. Although majority of the study population was compliant with wearing masks in public, results were unsatisfactory in terms of their etiquette. Effort is needed to increase the general public's concern in value of using face mask and awareness about correct techniques.

Keywords: Community; COVID-19; face mask; Islamabad; public compliance; PPE 


\section{Introduction}

$\mathrm{T}$ he widespread use of face masks in public has been shown to be an effective means of reducing the transmission rate of SARS-CoV2 (1). Recent studies have stressed upon their utilization as a valuable source control measure that can also be applied to the public (2). As a sole intervention, face masks probably exert little influence on epidemic outcomes. However, when implemented with social distancing and hand hygiene, they ultimately produce significant decreases in virus transmission, leading to reduced mortality, healthcare system burden and economic impact (3). Face mask usage is an intervention that brings moderate benefits at an individual level but has larger population benefits (4). The World Health Organization (WHO) has recently updated its guidelines on the use of face masks by the public in light of this fact (1). It has also suggested that countries use an individual risk-based approach while taking into account local epidemiology, challenges of social distance, resources, culture and community preferences (5).

Pakistan is a country with fragile economy which could not afford strict lock downs. Physical distancing and other hygiene measures were difficult to implement in our social structure. The crisis was further compounded by a high nationwide positivity ratio with insufficient capacity to enforce supplementary measures including contact tracing, country-wide testing and isolation of suspected/confirmed cases $(6,7)$. Face masks thus seemed to be an effective strategy for controlling the current COVID-19 pandemic for a resource-limited country such as Pakistan. The Institute for Health Metrics and Evaluation (IHME) issued a warning to Pakistan in June, fearing an alarming death toll due to COVID-19 by October (8). It urged aggressive measures including use of face masks by all Pakistanis in public places. The Ministry of National Health Services, Regulations \& Coordination (NIH) also revised their guidelines making it mandatory for all to wear a facemask whenever leaving their homes at all times, especially at crowded public places, mosques, bazaars, shopping malls, public transport i.e. roads, rails and flights (9). Despite warnings issued by such institutions as well as the government, public response was indifferent and the country witnessed a second deadly spell of COVID-19 in October $(7,10)$.
Mathematical modeling suggests that if a mask is $60 \%$ effective at blocking viral transmission and is worn by $60 \%$ of the population, it will reduce the transmission rate to below 1.0 (11). This means that one person would be infecting only one other individual, causing the disease to eventually die out (12). Worth mentioning here is the significance of face masks against asymptomatic transmission. Such individuals are responsible for approximately $79 \%$ of new infections (13). The population-level benefit would thus be far greater if a nation-wide mass-masking policy is adopted. An analysis of recommendations on face mask use in different community settings around the globe highlights how effective this strategy has been in curbing COVID-19 $(11,14,15,16)$. The WHO and Centre of Disease Control (CDC) have advocated the use of face masks in public. However, role of coherent government messaging and cultural beliefs cannot be ruled out when it comes to community practices. WHO has advised governments to develop their own policies for raising awareness of people on the correct usage and disposal of face mask. It also urges countries to conduct research and compile evidence pertaining to the impact and effectiveness of this intervention at a community level (5).

Multiple studies on use of face mask have been conducted in healthcare settings but published literature in community settings remains lacking in Pakistan (17). While there are studies describing the effectiveness of widespread mask wearing, there is sparse literature on mask compliance and practices in the community (7). There is now ample evidence to suggest that mask wearing; if widespread enough can be a successful COVID-19 prevention strategy (1). However, the proportion of the population that wears masks and practices proper technique remains largely unknown. Since the effectiveness of masks as a preventive measure is directly related to its correct use and disposal practices (11), it is imperative to gain further insight into mask compliance. Our study data would allow policy makers to gauge the effectiveness of their COVID-19 awareness campaigns. Furthermore, by illustrating which demographics are least likely to be compliant, and the factors that prevent them from complying. We hope to provide suggestions to policy makers on how best to target and implement public health awareness programs to combat the pandemic of COVID-19. 


\section{Methodology}

The study was conducted after ethical approval from the Institutional Review Board of Fazaia Medical College (IRB-FMC). This is a descriptive crosssectional survey with a sample size of 165 , calculated by WHO sample size software at $95 \%$ confidence level and $15 \%$ relative precision with $51 \%$ prevalence of face mask use in general community (18). Out of 250 subjects approached for this study, a total of 190 who consented were included. Eligible participants included all people aged 18 years and above. Considering the knowledge differences in medical professionals and general population, health care professionals including, medical students, practicing doctors, nurses and allied health science graduates, were excluded from this study in order to control confounding effect of their level of knowledge. Participants were recruited in between November and December, via convenient sampling from various public areas of Islamabad in order to get a sample from each socio-economic stratum. All variables of interest were measured using a self-developed questionnaire based on the guidelines from the WHO and NIH $(1,9)$. The questionnaire was assessed by three different Public Health Scientists in order to check its internal validity and was finalized after making amendments based on their suggestions. All participants were given a brief overview of the study, their anonymity assured and verbal consent taken. The questionnaire was administered in the form of face-to-face structured interviews by the researchers themselves and specific measures were taken to minimize the Hawthorne effect.

Face mask compliance in this study was considered as abiding by the regulations set by the $\mathrm{WHO}$ and $\mathrm{NIH}$ on face mask usage. Practicing hand hygiene before and after putting on mask is essential. The mask should ideally not be touched or adjusted once worn. It should not be lowered while talking. A disposable mask is to be replaced with a new one after a single use and is not to be re-cycled. It should be removed from behind and discarded immediately in a closed bin. Cloth masks should be washed regularly $(1,9)$.

Data was entered and analyzed using SPSS version 23.0 with a margin of error of $5 \%(\alpha=0.05)$. Mean and standard deviation was computed for continuous variables like age, while proportions were computed for categorical variables and results were presented in the form of figures and tables. Chi-square test was used to see the association between knowledge and etiquettes about facemasks use and to see the effects of demographic variables on them.

\section{Results}

Out of a sample size of 190, majority were adults $(40 \%)$, graduates $(62.1 \%)$, male $(61.1 \%)$ and doing jobs $(34.7 \%)$. Over fifty-five percent people said that they were not concerned about the Covid-19 pandemic (Table1). Educational level of participants was categorized into four, "illiterate \& primary" category comprised equally of illiterate and those who had primary education.

Table 1: Characteristics of the Study Participants

\begin{tabular}{|c|c|c|}
\hline Characteristics & $\begin{array}{l}\text { Frequency } \\
\text { (N) }\end{array}$ & Percentage (\%) \\
\hline $\begin{array}{l}\text { Gender } \\
\text { Male } \\
\text { Female }\end{array}$ & $\begin{array}{l}116 \\
74\end{array}$ & $\begin{array}{l}61.1 \\
38.9\end{array}$ \\
\hline $\begin{array}{l}\text { Age in years } \\
\text { Young adult (19-24) } \\
\text { Adult (25-44) } \\
\text { Middle aged (45-64) } \\
\text { Aged (65 and above) }\end{array}$ & $\begin{array}{l}64 \\
77 \\
37 \\
12\end{array}$ & $\begin{array}{l}33.7 \\
40.5 \\
19.5 \\
6.3\end{array}$ \\
\hline $\begin{array}{l}\text { Education } \\
\text { Illiterate \& Primary } \\
\text { Matriculation } \\
\text { Intermediate } \\
\text { Graduation }\end{array}$ & $\begin{array}{l}20 \\
20 \\
32 \\
118\end{array}$ & $\begin{array}{l}10.5 \\
10.5 \\
16.9 \\
62.4\end{array}$ \\
\hline $\begin{array}{l}\text { Occupation } \\
\text { Businessmen } \\
\text { Employees } \\
\text { Students } \\
\text { Housewives } \\
\text { Retired }\end{array}$ & $\begin{array}{l}27 \\
66 \\
54 \\
32 \\
11\end{array}$ & $\begin{array}{l}14.2 \\
34.7 \\
28.4 \\
16.8 \\
5.8\end{array}$ \\
\hline $\begin{array}{ll}\text { Concerned } & \text { about } \\
\text { COVID-19 } & \\
\text { Yes } & \\
\text { No } & \end{array}$ & $\begin{array}{l}106 \\
84\end{array}$ & $\begin{array}{l}55.8 \\
44.2\end{array}$ \\
\hline $\begin{array}{l}\text { Leaving house } \\
\text { Daily } \\
\text { Frequently (every } \\
\text { other day) } \\
\text { Seldom (once a }\end{array}$ & $\begin{array}{l}87 \\
32 \\
71\end{array}$ & $\begin{array}{l}45.8 \\
16.8 \\
37.4\end{array}$ \\
\hline week or less) & & \\
\hline
\end{tabular}


Figure 1 shows that approximately two thirds of the participants always wore face masks when leaving their homes that is they were compliant to face mask. Among the remaining who were non-compliant to face mask, $50 \%$ were using mask only in public places while $40 \%$ and $10 \%$ used mask seldom or never respectively. But at the time of interview we observed that $76 \%$ of participants wore mask.

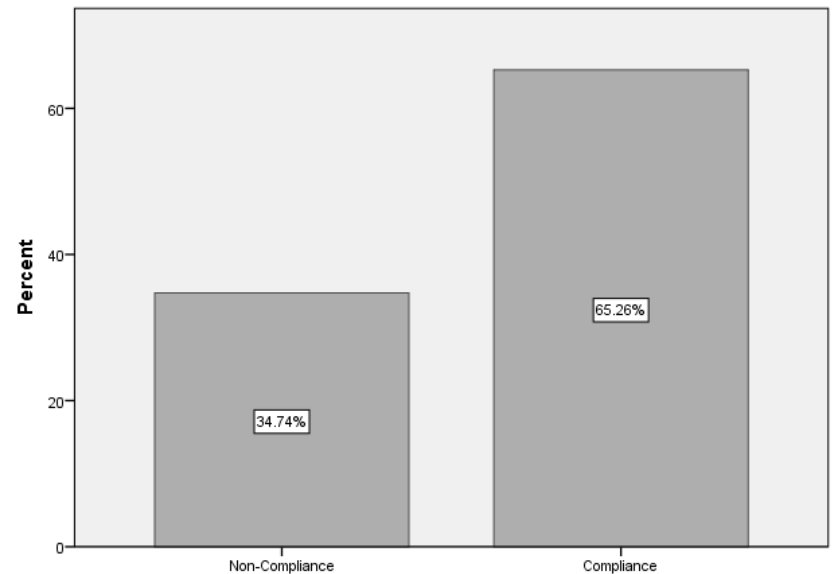

Figure 1: Proportion of participants compliant to face mask

Knowledge and ensuing etiquettes about National policy on face mask

The present study showed that two-thirds $(67.9 \%)$ of respondents were unaware of the existence of any national policy concerning face mask use. The majority $(73.2 \%)$ perceived that national policy would be in favor of using mask by everyone. More than half (57.4\%) incorrectly considered surgical masks to be best for general public use, while only 22 subjects $(11.2 \%)$ identified cloth masks as the best masks for public use (as recommended by the WHO). Personal discomfort was identified as the commonest barrier in face mask use (71\%). Cost and loss of social interaction were the other two causes equally pointed out by $7 \%$ of participants. Only 15\% were found to wear face mask facing no obstacle. Forty two persons (22\%) out of the study population incorrectly presumed that wearing masks reduces the need for further precautions i.e. hand hygiene and social distancing.

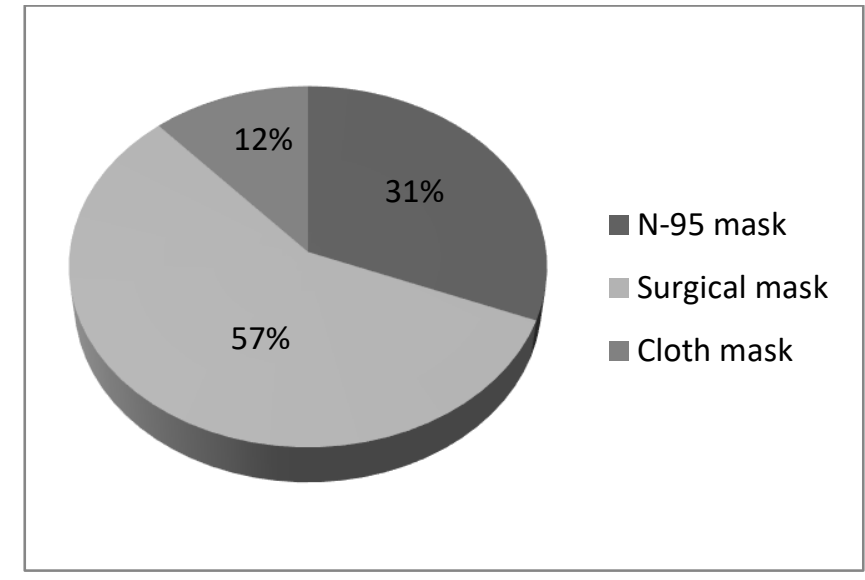

Figure 2: Type of mask preferred for the use of general public

Figure 3 shows proportion of responses to questions related to practicing etiquettes of wearing face mask. Large number of participants $(76.8 \%)$ were in habit of touching their masks, $35.8 \%$ did not wash their hands before and after using face mask. One quarter admitted that they lowered their masks during conversation and $66 \%$ were using a disposable mask multiple times. Practice pertaining to the removal of face mask was adequate (85\%) however its proper disposal in a closed bin was observed by less than half $(40 \%)$ of the population. Correct response on each etiquette related question scored " 1 " and incorrect scored " 0 ". The mean score on etiquette related questions was 3.73 with a standard deviation of 1.18 . The participants were categorized on the basis of score, those who scored 6 and those scored 5 or less were labelled as with "proper" and "improper" etiquettes practices.

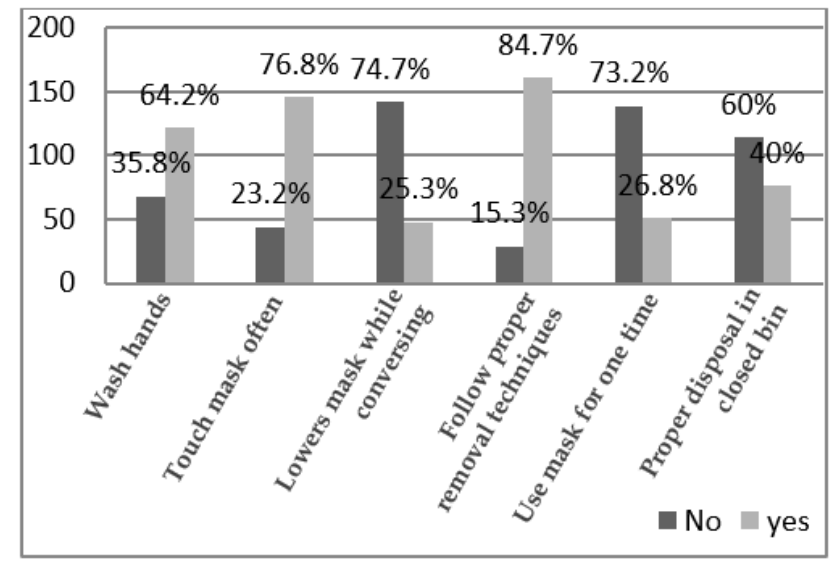

Figure 3: Responses of participants on face masks etiquette related questions 
It was observed that only $9(4.7 \%)$ of them were following the proper etiquettes. Only half of the participants $(55 \%)$ correctly stated that wearing a face mask can protect them and others from Covid-19 infection.

\section{Cross-tabulation}

While concerned subjects were more likely to be wearing masks (Fisher Exact test with $\mathrm{p}<0.05$ ), 31\% of them were non-compliant when questioned.

Socio-demographic variables were cross tabulated with face mask compliance and etiquettes and ChiSquare or Fisher's Exact test was applied to assess their association as shown in Table 2. It was observed that being adult, house wives, having completed graduation or being a student made them more compliant to face mask as compared to others but the difference was statistically insignificant. Females were more compliant to face mask use than males and this association was found to be significant $(p=0.02)$.

Table 2: Cross-tabulation of Compliance and Etiquettes of face mask with Socio-demographic characteristics of participants

\begin{tabular}{|c|c|c|c|c|c|c|}
\hline \multirow{2}{*}{$\begin{array}{l}\text { Socio- } \\
\text { demographic } \\
\text { characteristics }\end{array}$} & \multicolumn{3}{|c|}{ Compliance to Face Mask } & \multicolumn{3}{|c|}{ Following Proper Etiquettes } \\
\hline & $\begin{array}{l}\text { Yes } \\
\text { N (\%) }\end{array}$ & $\begin{array}{l}\text { No } \\
\text { N (\%) }\end{array}$ & $\begin{array}{l}\text { p } \\
\text { value } \\
\text { a }\end{array}$ & $\begin{array}{l}\text { Yes } \\
\text { N (\%) }\end{array}$ & \begin{tabular}{|l} 
No \\
N (\%)
\end{tabular} & $\begin{array}{l}\text { p } \\
\text { value }^{b}\end{array}$ \\
\hline $\begin{array}{l}\text { Gender } \\
\text { Male } \\
\text { Female }\end{array}$ & $\begin{array}{ll}68 & (58.6) \\
56 & (75.7)\end{array}$ & $\begin{array}{ll}48 & (41.4) \\
18 & (24.3)\end{array}$ & $0.02 *$ & $\begin{array}{l}7(6) \\
2(2.7)\end{array}$ & $\begin{array}{l}109(94) \\
72(97.3)\end{array}$ & 0.49 \\
\hline $\begin{array}{l}\text { Age } \\
\text { Young adult } \\
\text { Adult } \\
\text { Middle aged } \\
\text { Aged } \\
\end{array}$ & \begin{tabular}{|l}
$42(65.6)$ \\
$55(71.4)$ \\
$20(54.1)$ \\
$7(58.3)$
\end{tabular} & \begin{tabular}{|l}
$22(34.4)$ \\
$22(28.6)$ \\
$17(45.9)$ \\
$5(41.7)$ \\
\end{tabular} & 0.31 & $\begin{array}{ll}0 & (0) \\
7 & (9.1) \\
2 & (5.4) \\
0(0)\end{array}$ & \begin{tabular}{|l}
$64(100)$ \\
$70(90.9)$ \\
$35(94.6)$ \\
$12(100)$ \\
\end{tabular} & 0.05 \\
\hline $\begin{array}{l}\text { Education } \\
\text { Up to primary } \\
\text { Matriculation } \\
\text { Intermediate } \\
\text { Graduation }\end{array}$ & \begin{tabular}{|l}
$11(55)$ \\
$11(55)$ \\
$19(59.4)$ \\
$83(70.3)$ \\
\end{tabular} & $\begin{array}{l}9(45) \\
9(45) \\
13(40.6) \\
35(29.7)\end{array}$ & 0.30 & \begin{tabular}{|ll}
1 & $(5)$ \\
3 & $(15)$ \\
$0(0)$ \\
$5(4.2)$
\end{tabular} & $\begin{array}{l}19(95) \\
17(85) \\
32(100) \\
113(95.8) \\
\end{array}$ & 0.09 \\
\hline $\begin{array}{l}\text { Occupation } \\
\text { Businessmen } \\
\text { Employees } \\
\text { Students } \\
\text { Housewives } \\
\text { Retired } \\
\end{array}$ & $\begin{array}{l}14(51.9) \\
44(66.7) \\
37(68.5) \\
22(68.8) \\
7(63.6)\end{array}$ & $\begin{array}{ll}13 & (48.1) \\
22 & (33.3) \\
17 & (31.5) \\
10 & (31.2) \\
4 & (36.4)\end{array}$ & 0.62 & \begin{tabular}{|ll}
3 & $(11.1)$ \\
3 & $(4.5)$ \\
0 & $(0)$ \\
2 & $(6.3)$ \\
1 & $(9.1)$ \\
\end{tabular} & $\begin{array}{ll}24 & (88.9) \\
63 & (95.5) \\
54 & (100) \\
30 & (93.8) \\
10 & (90.9)\end{array}$ & 0.09 \\
\hline
\end{tabular}

a Chi square test applied $\quad$ * significant $p$-value $<0.05$

$b$ Fisher's Exact test was applied as Chi square test was inapplicable

\section{Discussion}

In the present study, two thirds (65.2\%) of the sample population was found to be compliant with wearing a face mask. Face mask usage by general public of Hong Kong during the ongoing pandemic was $96.6 \%$.
Countries such as China and South Korea also reported high figures of $98.3 \%$ and $85.7 \%$ respectively. However, figures reported from U.S. and Western Europe were much lower $(2.1 \%$ \& $1.4 \%$ respectively). A suitable explanation for these findings is the prior experience of SARS outbreak in 2003 by these Asian countries (14). In addition, face mask usage in many Asian countries is easier to inculcate as a cultural norm while face mask users in West are more likely to face stigmatization in society (19). Adult population was the most compliant group (71.4\%) and middle aged persons the least compliant (54.1\%). This is in contrast to studies from West which conclude elderly population to be the most compliant group with wearing face mask $(20,21)$. This can be explained by the difference in our cultural and moral value systems. Elderly in West are less likely to be cared at home by family and are either independent or at best receive institutional care. Logically, they are more concerned about COVID-19 and their higher risk for severe illness (21).

Approximately $45 \%$ people in our study population commuted on a daily basis. Of these, only $55.1 \%$ routinely wore a mask. In our study, the major barrier observed in masking was personal discomfort (71\%), which has been a subject of many previous studies (22, 23). Interestingly, cost seemed to be a serious concern for only $6.8 \%$ people in our study despite the fact that Pakistan is a resource-limited country. The only explanation of this could be that most people did not discard their mask after single use. The results of our study confirmed that three quarters of study population $(73.2 \%)$ did not dispose their single use masks as per recommendation. Italy has been one of the most hard-hit countries in the COVID-19 pandemic and a recent Italian study concluded that $70.5 \%$ of their public threw used masks in general waste and only $13.4 \%$ in specific waste baskets (24). This is an alarming finding because face masks can serve as a vector for transmission of COVID-19 if not properly maintained and cleaned after every use or thrown away (25). Another study conducted in China revealed similar results where only $7.6 \%$ of the subjects discarded used masks into closed bins (26). The results of our study commensurate with the findings of these two studies with only two fifths of our population $(40 \%)$ exhibiting safe mask disposal into closed bins. A likely reason for such malpractices is lack of awareness. Campaigning in our country has 
primarily focused on wearing of mask and not its proper disposal.

The national policy on face masks demands that the Pakistani public wear non-medical fabric masks at all times outside of home while practicing social distancing and proper hand hygiene (9). It is unfortunate that three quarters $(67.9 \%)$ of our study population was still not aware of this policy. This can be attributed to the fact that this information is available only on the website of our national health ministry and is not reaching the masses. Instead of being restricted to electronic media the government must make a conscious effort to advertise this policy utilizing any other means possible such as newspapers and television. Majority of the people $(88.2 \%)$ believed medical masks to be the best type of face mask for general public use. Of these $30.81 \%$ considered N95 mask to be the first choice while $57.4 \%$ preferred surgical mask over all other masks. This is an unnerving finding given that surgical masks and N95 respirators are classified as personal protective equipment (PPE) and their use in public settings may divert this critical resource from health care workers. Cloth masks are known for their reasonable efficacy (27), sustainability (28), and cost effectiveness (23). The increasing shortage of PPE for health care workers worldwide has led health authorities to recommend cloth mask for general public use (29). Fabric masks are now the predominant type of mask worn by general public in Japan (95.1\%), South Korea (84.8\%), Western Europe (85.7\%), and US (100\%) (30). In contrast, only $11.2 \%$ people in our study recommended their use for the general public and only $6.8 \%$ were found to be wearing them. Similar results were reported from Italy where surgical masks $(80.6 \%)$ were the most common masks used in community settings (24).

While three quarters (65.2\%) of the Pakistani population wore a mask during the ongoing pandemic, a mere 5\% followed all the correct techniques of face mask use, rendering the practice ineffective. As opposed to this, a recent study from China revealed that nearly all $(99 \%)$ people wore a mask during the COVID-19 pandemic and most $(73.3 \%)$ demonstrated good usage etiquette (26). Hand hygiene before and after face mask use can reduce inadvertent contact between the face and contaminated hands (31). Case-control studies suggest that wearing a mask alone is effective up to $68 \%$ in reducing transmission; however, when combined with hand hygiene and other measures it becomes over $91 \%$ effective (32). Interestingly, nearly two-thirds of our study population $(64.2 \%)$ performed hand hygiene before and after mask use. In a Chinese study by Tan et al, participants seldom cleaned their hands before putting on a face mask, and more than half failed to consistently wash their hands afterward (26). This difference in behavior could reflect our religious practices as a Muslim country. An integral component of Islam is ablution prior to prayer. In addition to this Muslims also tend to wash hands regularly before and after meals or visiting the bathroom. Increased manipulation of face mask while in use is related to an increased risk of self-contamination (22). One fifth $(25.3 \%)$ of our study population agreed to lowering their face masks during conversation and three quarters $(76.8 \%)$ habitually touched it while wearing. This practice is in contrast to regions like China, South Korea and Europe where face-touching behaviors were negligible being observed in $1.1 \%, 2.2 \%$ and $6.1 \%$ respectively (33). Another observation highlighted by our study was that nearly one fifth of the subjects erroneously believed they did not need to practice social distancing and hand hygiene when wearing a face mask. This is of concern because the WHO has continuously reiterated the fact that masks are not a substitute for social distancing, hand and respiratory hygiene (1).

Fear of contracting the disease with associated anxiety and depression is a well-documented phenomenon (34). Despite this, the present study revealed that more than half of our study population $(56.8 \%)$ was not concerned about the spread of disease or its impact on their lives. While the results of our study cannot be extrapolated to whole Pakistani population, the fact that it was conducted in Islamabad makes it noteworthy. Islamabad is the capital city of Pakistan and represents a population dominated by middle and upper middle class citizens with a better general awareness and education level. The lack of concern for spread of COVID-19 combined with unsatisfactory face mask compliance and awareness regarding its correct use could very well explain the alarming rise of COVID-19 in the second wave.

A major limitation of our study was its relatively small sample size during the smart lockdown. To overcome this limitation, we collected data from several prominent sectors of Islamabad and included subjects from all strata. Despite that the results of our study cannot be generalized to whole Pakistani population 
and further large scale studies are required to further explore this aspect. To minimize the errors with selfreported practice, questions pertaining to mask usage etiquette were also directly observed by researchers so that participant's actual performance could be recorded accurately. To the best of our knowledge all studies in Pakistan regarding face mask use have so far been conducted on health care workers in hospital settings, making this study the first of its kind at a community level.

\section{Conclusion}

The study concluded that the Pakistani community is unaware of our national policy on face masks and does not know that cloth mask is the recommended mask for use by general public. Though the compliance to face mask was good but it was still not up to the mark in our study participants and very few of them were following proper techniques of using face mask. Females were more compliant to face mask than males $(p<0.05)$.

Prospects for benefits with a low cost intervention lead us to strongly recommend compliance with the government policy of nation-wide face masking to achieve a substantial reduction in the transmission rate of the virus. We believe that as with recent hand washing campaigns, mass education about the etiquettes of masks should be emphasized. Widespread promotion and adoption of re-usable and washable cloth face masks by general public is advocated to conserve PPE resources for our health care workers.

\section{References}

1. World Health Organization. Mask use in the context of COVID-19: interim guidance, 1 December 2020. World Health Organization; 2020.

2. Leung NH, Chu DK, Shiu EY, Chan KH, McDevitt JJ, Hau BJ, Yen HL, Li Y, Ip DK, Peiris JM, Seto WH. Respiratory virus shedding in exhaled breath and efficacy of face masks. Nature medicine. 2020 May;26(5):676-80.

3. Eikenberry SE, Mancuso M, Iboi E, Phan T, Eikenberry K, Kuang Y, Kostelich E, Gumel AB. To mask or not to mask: Modeling the potential for face mask use by the general public to curtail the COVID-19 pandemic. Infectious Disease Modelling. 2020 Jan 1;5:293-308.
4. Cheng KK, Lam TH, Leung CC. Wearing face masks in the community during the COVID-19 pandemic: altruism and solidarity. The Lancet. 2020 Apr 16.

5. World Health Organisation. COVID 19 STRATEGY UPDATE [Internet]. 2020. Available from: https://www.who.int/docs/default-

source/coronaviruse/covid-strategy-update14april2020.pdf?sfvrsn=29da3ba0_6

6. Health Advisory Platform by Ministry of National Health Services Regulations and Coordination. (2020, December 19). Retrieved December 6, 2020, from https://covid.gov.pk/stats/ict

7. Noreen N, Naveed I, Dil S, Niazi S, Saleem S, Mohiuddin N, Khan N, Noor B, Khan M, Khan F. Trend Analysis of exponential increase of Covid-19 cases in Pakistan: An interpretation. Global Biosecurity. 2020 Oct $19 ; 1(4)$.

8. COVID-19 Results Briefing: Pakistan [Internet]. Healthdata.org. 2020 [cited 10 November 2020]. Available from: http://www.healthdata.org/sites/default/files/files/P rojects/COVID/briefing_Pakistan_20201029.pdf

9. Ministry of National Health services, COVID-19 Advisory Board. (2020, December 11). Guidelines for Mandatory Use of Face Mask [Press release]. Retrieved December 12, 2020, from https://storage.covid.gov.pk/new_guidelines/11Dece mber2020_20201211_Guidelines_for_mandatory_use_of _face_mask_1705.pdf

10. After three months: Pakistan records highest single-day surge in corona cases. (2020, October 25). Https://www.thenews.com.pk/. Retrieved November 1, 2020, from https://www.thenews.com.pk/print/734510-afterthree-months-pakistan-records-highest-single-daysurge-in-corona-cases

11. Greenhalgh T. Face coverings for the public: Laying straw men to rest. Journal of Evaluation in Clinical Practice. 2020 Aug;26(4):1070-7.

12. Tian L, Li X, Qi F, Tang QY, Tang V, Liu J, Li Z, Cheng $X, \operatorname{Li} X$, Shi Y, Liu H. Calibrated intervention and containment of the COVID-19 pandemic. arXiv preprint arXiv:2003.07353. 2020 Mar 16.

13. Li R, Pei S, Chen B, Song Y, Zhang T, Yang W, Shaman J. Substantial undocumented infection facilitates the rapid dissemination of novel coronavirus (SARS-CoV2). Science. 2020 May 1;368(6490):489-93.

14. Cheng VC, Wong SC, Chuang VW, So SY, Chen JH, Sridhar S, To KK, Chan JF, Hung IF, Ho PL, Yuen KY. The role of community-wide wearing of face mask for control of coronavirus disease 2019 (COVID-19) epidemic due to SARS-CoV-2. Journal of Infection. 2020 Jul 1;81(1):107-14.

15. Wang CJ, Ng CY, Brook RH. Response to COVID-19 in Taiwan: big data analytics, new technology, and proactive testing. Jama. 2020 Apr 14;323(14):1341-2. 


\section{Compliance and Etiquettes of Using Face Masks in Public During Covid-19 Pandemic: A Community-Based Survey from Islamabad, Pakistan}

16. Feng S, Shen C, Xia N, Song W, Fan M, Cowling BJ. Rational use of face masks in the COVID-19 pandemic. The Lancet Respiratory Medicine. 2020 May 1;8(5):434-6.

17. Sarfraz S, Raza MR, Aziz K, Umar M, Noreen K, Shehryar M. Compliance on the use of different types of face mask by healthcare workers and general public in tertiary care hospital of RMU during COVID-19 pandemic. Journal of Rawalpindi Medical College. 2020 Aug 16;24(Supp-1):71-6.

18. Mohamad EM, Azlan AA, Hamzah MR, Tham JS, Ayub $\mathrm{SH}$. Public knowledge, attitudes and practices towards COVID-19: A cross-sectional study in Malaysia. medRxiv. 2020 Jan 1.

19. Wong, T., 2020. Coronavirus: Why some countries wear face masks and others don't. BBC, [online] Available at: <https://www.bbc.com/news/world-52015486> [Accessed 10 December 2020].

20. Taylor M, Raphael B, Barr M, Agho K, Stevens G, Jorm L. Public health measures during an anticipated influenza pandemic: Factors influencing willingness to comply. Risk management and healthcare policy. 2009;2:9.

21. Hutchins HJ, Wolff B, Leeb R, Ko JY, Odom E, Willey J, Friedman A, Bitsko RH. COVID-19 mitigation behaviors by age group-United States, April-June 2020. Morbidity and Mortality Weekly Report. 2020 Oct 30;69(43):1584.

22. Matusiak Ł, Szepietowska M, Krajewski P, BiałynickiBirula R, Szepietowski JC. Inconveniences due to the use of face masks during the COVID-19 pandemic: a survey study of 876 young people. Dermatologic therapy. $2020 \mathrm{Jul} 1$.

23. Abaluck J, Chevalier JA, Christakis NA, Forman HP, Kaplan EH, Ko A, Vermund SH. The case for universal cloth mask adoption and policies to increase supply of medical masks for health workers. Available at SSRN 3567438. 2020 Apr 1.

24. Scalvenzi M, Villani A, Ruggiero A. Community knowledge about the use, reuse, disinfection and disposal of masks and filtering facepiece respirators: results of a study conducted in a dermatology clinic at the University of Naples in Italy. Journal of Community Health. 2020 Nov 30:1-8.
25. Kwon JH, Burnham CA, Reske KA, Liang SY, Hink T, Wallace MA, Shupe A, Seiler S, Cass C, Fraser VJ, Dubberke ER. Assessment of healthcare worker protocol deviations and self-contamination during personal protective equipment donning and doffing. Infection control \& hospital epidemiology. 2017 Sep;38(9):1077-83.

26. Tan M, Wang $\mathrm{Y}$, Luo $\mathrm{L}, \mathrm{Hu}$ J. How the public used face masks in China during the coronavirus disease pandemic: A survey study. International journal of nursing studies. 2021 Mar 1;115:103853.

27. Konda A, Prakash A, Moss GA, Schmoldt M, Grant GD, Guha S. Aerosol filtration efficiency of common fabrics used in respiratory cloth masks. ACS nano. 2020 Apr 24;14(5):6339-47.

28. Rothe M, Rohm E, Mitchell E, Bedrosian N, Kelly C, String G, Lantagne DS. A systematic review of mask disinfection and reuse for SARS-CoV-2. medRxiv. 2020 Jan 1.

29. Beesoon S, Behary N, Perwuelz A. Universal masking during COVID-19 pandemic: Can textile engineering help public health? Narrative review of the evidence. Preventive medicine. 2020 Aug 11:106236.

30. Chen YJ, Qin G, Chen J, Xu JL, Feng DY, Wu XY, Li X. Comparison of face-touching behaviors before and during the coronavirus disease 2019 pandemic. JAMA network open. 2020 Jul 1;3(7):e2016924-.

31. Tweedy JT. Healthcare Safety for Nursing Personnel: An Organizational Guide to Achieving Results. CRC Press; 2014 Dec 10.

32. Jefferson T, Foxlee R, Del Mar C, Dooley L, Ferroni E, Hewak B, Prabhala A, Nair S, Rivetti A. Physical interventions to interrupt or reduce the spread of respiratory viruses: systematic review. Bmj. 2008 Jan 10;336(7635):77-80.

33. Tang CS, Wong CY. Factors influencing the wearing of facemasks to prevent the severe acute respiratory syndrome among adult Chinese in Hong Kong. Preventive medicine. 2004 Dec 1;39(6):1187-93.

34. Ahorsu DK, Lin CY, Imani V, Saffari M, Griffiths MD, Pakpour AH. The fear of COVID-19 scale: development and initial validation. International journal of mental health and addiction. 2020 Mar 27:1-9. 